\title{
A COMPARATIVE STUDY OF STEROID INJECTION WITH OR WITHOUT LIGNOCAINE IN TREATING FROZEN SHOULDER
}

\author{
Dr A Pandey ${ }^{1}$, Dr B Shrestha ${ }^{2}$, Dr KM Shrestha ${ }^{2}$
}

ABSTRACT

\section{BACKGROUND:}

Treatment of Frozen shoulder (Adhesive Capsulitis) is mainly nonoperative. Intra-articular steroid injections and physiotherapy are one of the most effective and useful treatment. Even though intra-articular steroid injections are very effective in inflammatory phase of the disease; patients are reluctant to move their affected shoulder for fear of pain. Thus, they do not follow exercise program properly resulting in poor outcomes.

\section{OBJECTIVE:}

If pain could be reduced, outcome of treatment can improve. Lignocaine, when combined with steroid injection, plays an important role in immediate improvement of pain and active range of motion thereby increasing the overall result.

\section{MATERIALS \& METHODS:}

100 patients with frozen shoulder were selected according to predetermined inclusion and exclusion criteria. After randomization by sealed envelope technique, patients were divided into Group A and Group B. Group A patients were injected with $2 \mathrm{ml}(80 \mathrm{mg}$ ) of methylprednisolone and $3 \mathrm{ml}$ of $1 \%$ Lignocaine, and Group B patients were injected with 2 $\mathrm{ml}(80 \mathrm{mg})$ of methylprednisolone and $3 \mathrm{ml}$ of Distilled water in the affected shoulder via standard posterior approach. Then half an hour of standard shoulder range of motion (ROM) exercise regimen was performed under supervision. Pre injection and post injection pain level was scored by Visual Analogue Score (VAS) and Subjective satisfaction score (SSS). Shoulder exercises were taught and home based physiotherapy was carried out by patients themselves. They were also prescribed oral analgesics for 5 days and were followed at 1, 3, and 6 weeks. At every follow up visit, they were assessed for improvement via Constant-Murley Score (CMS).

\section{RESULTS:}

The mean age of this study in group A and group B was 56.46 years (SD 10.05) and 57.18 years (SD 8.87) respectively (P 0.70). There were 31 male and 19 female in group A as compared to group B where there was 26 males and 24 females (P 0.41). In both the groups, maximum number of patients presented at around 10 weeks. In both the groups left side dominated right side with equal frequency (33 left sides and 17 right sides) (P 1.00) and non dominant side outnumbered dominant side with near equal frequency (P 1.00). After the intervention, excellent result in SSS was observed only in group A whereas maximum patients of Group B had only fair result (42 patients). There was statistically significant difference between two groups in terms of pain; Activity of daily living (ADL) and Range of motion (ROM). Patients in group A were able to carry more weight than group B. In CMS 1 and 6 week total, there was statistically highly significant difference between two groups. 


\section{CONCLUSION:}

Even though steroid and physical exercises play important role in managing frozen shoulder, addition of lignocaine to steroid injection seems to be helpful. It relieves immediate pain on movement and improves exercise compliance thereby improving early outcomes. Evaluation of long term benefits of lignocaine injection needs further studies.

KEYWORDS: Frozen shoulder, intra-articular, lignocaine, steroid

1. Associate Professor, Department of Orthopaedics, Universal College of Medical Sciences, Bhairahawa, Nepal

2. Lecturer, Department of Orthopaedics, Universal College of Medical Sciences, Bhairahawa, Nepal

For correspondence:

Dr. Alok Pandey

Asosciate Professor,

Department of Orthopaedics

Universal College of Medical Sciences,

Bhairahawa, Nepal

Email: 


\section{INTRODUCTION}

Primary adhesive capsulitis, or "frozen shoulder," is a common condition encountered in the outpatient orthopaedic clinic. This condition has a prevalence of $2 \%$ to $5 \%$ in the outpatient setting ${ }^{1,2}$ but in patients with insulin-dependent diabetes mellitus, the prevalence increases to about $30 \%{ }^{3}$. It is characterized by the spontaneous onset of shoulder pain and global limitation of both active and passive shoulder motion. Frozen shoulder is more common in the fifth and sixth decades of life ${ }^{4,5}$, and other medical problems should be investigated in patients below 40 years of age. No racial predilection has been described in the literature; however, women are affected more than $\mathrm{men}^{4,6-8}$ with a ratio of $58: 42^{9}$. More recent studies showed male to female ratio of $1: 1^{10}$. It is generally agreed that the nondominant arm appears more likely to be involved6. However, Bunker et al, reports that the condition occurs with equal frequency in the left and right shoulders7. Frozen shoulder usually presents unilaterally and the incidence of subsequent involvement on the contra lateral side is $16-20 \%{ }^{2,5,11,12}$ however, a relapse is uncommon'.

The natural course of a frozen shoulder is usually selflimiting. Diagnosis of frozen shoulder is made clinically on the basis of pain and limitation of both active and passive range of shoulder motion. Although typically described as a self-limiting disease process ${ }^{13}$, the natural history of Frozen shoulder is not completely known, and recent studies have shown that it can lead to longer-term disability over the course of several years ${ }^{1,12,14,15}$. Most patients regain a full ROM; however, $10 \%$ to $15 \%$ of patients suffer from continued pain and limited $\mathrm{ROM}^{16}$

Many studies have attempted to establish the most effective treatment for frozen shoulder but much debate still remains. Currently there is no agreement on the standard management of this condition ${ }^{17}$. The lack of consensus on diagnostic criteria and concordance in clinical assessment complicates treatment choices. The controversy is due in part to a failure of many authors to precisely define and accurately identify frozen shoulder among other causes of shoulder pain and stiffness ${ }^{4,18}$.

Treatment of Frozen shoulder is mainly nonoperative, with most patients improving over a time period of 18 to 24months. Nonoperative treatment consists of non-steroidal anti-inflammatory drugs (NSAIDs), intra-articular steroid injections and physical therapy. Orthopaedic interventions that have been shown to produce successful outcomes in restoring function include; distension arthrography, manipulation under anaesthetic (MUA) and arthroscopic release.

Many people have demonstrated improvement in symptoms with intra-articular steroid injections. Carette et $\mathrm{al}^{19}$ showed significant improvement after treatment with steroid injections plus exercise versus exercise alone. Manipulation under anaesthetic (MUA) and arthroscopic capsular release should be reserved only for those patients who do not respond to conservative treatment after a minimum of 6 months of appropriate nonoperative treatment.

Intra-articular steroid injections can lead to satisfactory results in the treatment of Frozen shoulder, with improved range of motion and early pain reduction ${ }^{3}$. The intra-articular injection of lignocaine immediately before a physiotherapy session may relieve pain during the stretching and mobilization of the affected joint in patients with a frozen shoulder, thus enhancing the treatment effect. As physical therapy (Physiotherapy) is the prime factor for its treatment, immediate pain relief is a major determinant for the patients to follow $\mathrm{it}^{20}$. The early the start of physical therapy, the sooner and better is the outcome. In majority of cases the pain and disability associated with it demoralizes the patient, making many cases to lose the follow up and continuation of the physical therapy. In these situations Lignocaine by virtue of its immediate pain relief, helps in increase in the ROM within few minutes of administration. Half an hour of ROM exercises following steroid and lignocaine administration, gives psychological boost to the patient because of immediate pain relief which increases the compliance of patients and pursuance of the physical therapy regularly. A practical approach of intra-articular injection of lignocaine and steroid followed by stretching exercises and joint mobilization is a better method because it is quick and simple procedure.

Various studies had pointed out the effectiveness of intraarticular injection with different steroids but none of them had clearly pointed out the effectiveness of lignocaine that is frequently used during intra-articular injection. We assume that not only corticosteroid but lignocaine also plays a vital role in overall effectiveness of this method. We also believe that lignocaine gives immediate pain relief to the patient which is a turning step for overall recovery of the patients. Therefore, the purpose of the present study was to evaluate the difference in the effectiveness between intra-articular steroid injections with lignocaine and intra-articular steroid injections without lignocaine in treating patients with Frozen shoulder.

\section{MATERIALS \& METHODS}

This is a prospective randomized control study that was performed in Universal College of Medical Sciences Teaching Hospital (UCMSTH), Bhairahawa in the department of Orthopaedics and Trauma surgery. We recruited a total of 100 patients with frozen shoulder who attended the Orthopaedic outpatient department (OPD) of UCMSTH, Bhairahawa from January 2014 to January 2015. After approval from the Ethics Committee of the hospital patients were selected for the study. Patients were selected according to predetermined inclusion and exclusion criteria. Standard Inclusion Criteria ${ }^{21-23}$ were patients aged 40 to 70 years old, local shoulder pain, 
spontaneous onset of a painful stiff shoulder, marked loss of active and passive global shoulder motion with at least $50 \%$ loss of external rotation and normal x-rays on anteroposterior and axillary lateral radiographs of the glenohumeral joint. Exclusion Criteria ${ }^{19,22,24}$ were radiographic pathological findings or glenohumeral osteoarthritis on X-ray, clinical evidence of significant cervical spine disease, history of significant trauma to the shoulder, local steroid injection or any physiotherapy intervention to the affected shoulder within the last three months, cerebral vascular accident affecting the shoulder, inflammatory joint disease affecting the shoulder, bilateral frozen shoulder due to possible underlying systemic cause, thyroid disease, any coronary event, post coronary artery by-pass or catheterization prior to the clinical appearance of frozen shoulder, prior surgery, dislocation or fractures on the affected shoulder and active medico legal involvement. Inclusion criteria were representative of the typical features of frozen shoulder (Miller et $\mathrm{al}^{25}$ ). The exclusion criteria served to eliminate patients with an inappropriate diagnosis of frozen shoulder and patients with other inappropriate medical conditions complicating the pathology.

Informed consent was taken from all the patients who accepted to participate in the research work. Then all patients were randomized by using sealed envelope technique and then divided into Group A (Steroid and Lignocaine injection) and Group B (Steroid and Distilled water injection). Relevant history, clinical examination, X-ray shoulder joint and fasting blood sugar were obtained. The diagnosis of frozen shoulder was based on active and passive glenohumeral mobility which must be painful and limited. External rotation (ER) must be relatively more restricted than abduction and internal rotation (IR) and the shoulder pain should not be caused by another condition. The ranges of glenohumeral joint movement were considered normal as 900 abduction, 900 external rotation and 900 internal rotation. Patients rated their pain on Visual Analogue Scale (VAS) of 0 to 10 with 0 representing no pain and 10 the worst pain they had ever experienced. Pre-injection shoulder flexion, abduction, internal and external rotation were recorded. A uniform protocol of treatment was adopted. Group A patients were injected with $2 \mathrm{ml}(80 \mathrm{mg})$ of methylprednisolone and $3 \mathrm{ml}$ of 1\% Lignocaine, and Group B patients were injected with $2 \mathrm{ml}(80 \mathrm{mg})$ of methylprednisolone and $3 \mathrm{ml}$ of Distilled water in the affected shoulder without sonographic or fluoroscopic assistance. Before injection of steroid all patients were tested for lignocaine sensitivity by intradermal lignocaine injection. Then the patients were injected via standard posterior approach and half an hour of standard shoulder ROM exercise regimen was performed under supervision. Immediate pain relief and increase in ROM was observed and scored by VAS and Subjective satisfaction score. At every follow up visit, they were assessed for improvement via Constant Murley
Score $^{26}$. Low scores denote significant pain and poor function. Patients with unsatisfactory improvement at 6 weeks were injected again. No more than two injections were given to any patient.

All the data was statistically evaluated by standard statistical methods and analyzed with Statistical package for social science (SPSS) 21.

\section{RESULTS}

Basic clinical data regarding patient age, sex and other parameters are listed in table 1. Both the groups are nearly identical in all the parameters. (Table 1)

Table 1. Basic Clinical data of patients included in Group A and Group B

\begin{tabular}{|llll|}
\hline \multirow{2}{*}{$\begin{array}{l}\text { S.N. Clinical Information } \\
\text { Group A }\end{array}$} & Group B & \\
& & & \\
\hline 1. Mean Age & 56.46 & 57.18 & 0.70 \\
$\quad$ In years) & (SD 10.05) & (SD 8.87) & \\
2. Sex Male & 31 & 26 & \\
$\quad$ Female & 19 & 24 & 0.41 \\
3. Duration of pain & 23 & 19 & 0.56 \\
around 10 weeks & & & \\
4. Side affected /Dominant side & & & \\
$\quad$ Left & 33 & 17 & 1.00 \\
$\quad$ Right & 33 & 17 & \\
$\quad$ Non-dominant & 31 & 32 & 1.00 \\
$\quad$ Dominant & 19 & 18 & \\
5. Diabetics & 11 & 15 & 0.36 \\
6. Smokers & 24 & 22 & 0.68 \\
7. Reduced working & 50 & 50 & \\
capacity & & & \\
8. Light manual & 28 & 29 & \\
Workers & & & \\
\hline
\end{tabular}

Prior to intervention, out of 50 patients of group A, 36 patients had ER of 2 score (hand behind head and elbow forward) and 14 patients with ER of 4 score (hand behind head and elbow back). Out of 50 patients of group B, 38 patients had ER of 2 score and 12 patients with ER of 4 score (P 0.684). Regarding IR, most of the patients in both the group had 2 score (Positioning of dorsum of hand up to buttock) (25 patients in group A and 23 patients in Group B) (P 0.53).

After the intervention, excellent result in SSS was observed 
only in group A (24 patients) where as maximum patients in Group B had only fair result (42 patients) (P 0.00). (Fig. 1)

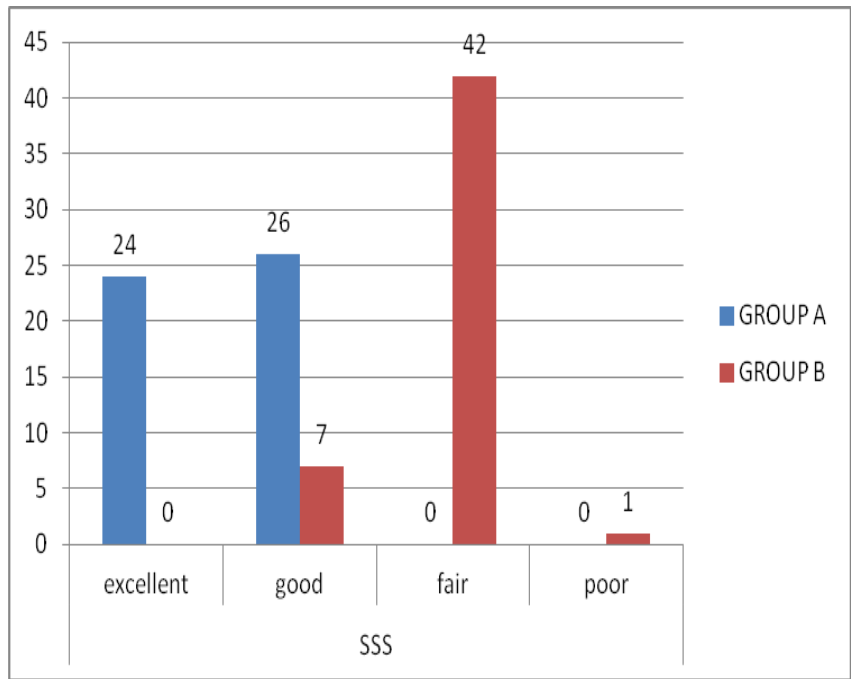

Fig. 1: Subjective satisfaction score (SSS) of group A and Group B. (P 0.00)

There was statistically significant difference between two groups in terms of all the parameters of pain. Nine patients in group A had no pain where maximum patients (32 patients) of group B reported mild to moderate pain (P 0.00). (Fig. 2)

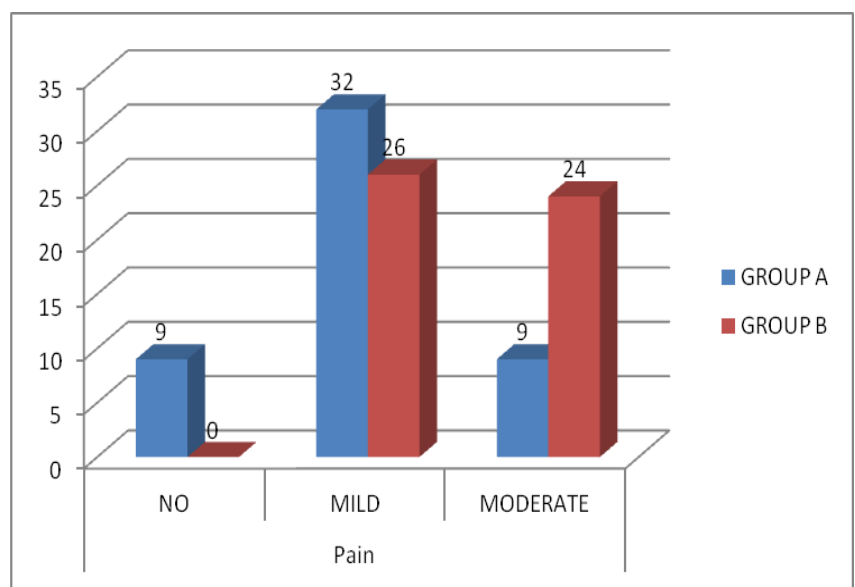

Fig. 2: Pain level in Group A and Group B. (P 0.00)

There was statistically significant difference between two groups in all the parameters of ROM. Fifteen patients of Group A had flexion of 150-1800 where as no patients from Group B had this range (P 0.00). In ROM abduction, 11 patients were able to abduct their arm between 150-1800 where as not a single patient from group $\mathrm{B}$ reported this range of motion (P 0.00). (Table 2)

Table 2. ROM Flexion and Abduction of Group A and Group B

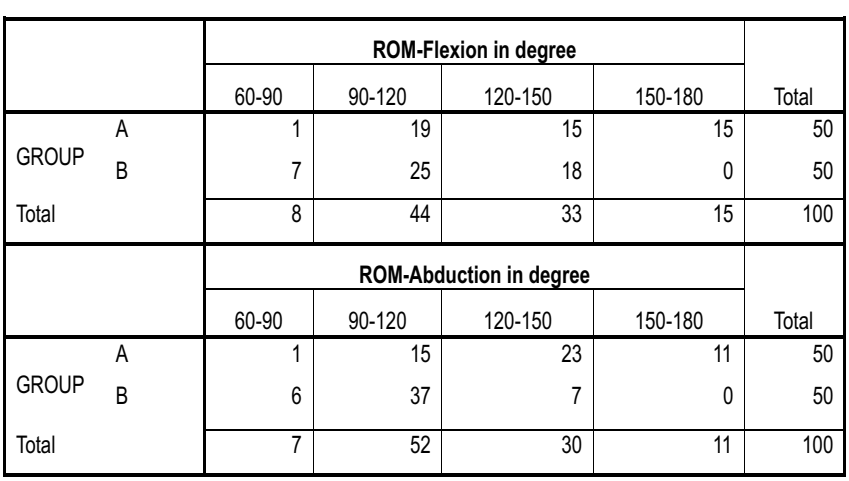

ROM: Range of Motion, ROM Flexion (P 0.00), ROM Abduction(P 0.00)

Seven patients from group A were able to perform full elevation of arm (P 0.00) and place their dorsum of hand between shoulder blades (P 0.00) whereas these ranges of motion were not observed in group B. (Table 3 )

Table 3. ROM- ER and IR of Group A and Group B

\begin{tabular}{|c|c|c|c|c|c|}
\hline & & \multicolumn{3}{|c|}{ ROM-ER } & \multirow[b]{2}{*}{ Total } \\
\hline & & $\begin{array}{l}\text { Hand above } \\
\text { head and elbow } \\
\text { forward }\end{array}$ & $\begin{array}{l}\text { Hand above } \\
\text { head and } \\
\text { elbow back }\end{array}$ & $\begin{array}{l}\text { Full elevation } \\
\text { of arm }\end{array}$ & \\
\hline \multirow{5}{*}{$\begin{array}{l}\text { GROUP } \\
\text { Total }\end{array}$} & $A$ & 14 & 29 & 7 & 50 \\
\hline & B & 37 & 13 & 0 & 50 \\
\hline & & 51 & 42 & 7 & 100 \\
\hline & & \multicolumn{3}{|c|}{ ROM-IR } & \multirow[b]{2}{*}{ Total } \\
\hline & & $\begin{array}{l}\text { Dorsum hand } \\
\text { to waist }\end{array}$ & $\begin{array}{l}\text { Dorsum hand } \\
\text { to } \mathrm{T} 12\end{array}$ & $\begin{array}{l}\text { Dorsum hand } \\
\text { between } \\
\text { shoulder } \\
\text { blades }\end{array}$ & \\
\hline \multirow{3}{*}{$\begin{array}{l}\text { GROUP } \\
\text { Total }\end{array}$} & $A$ & 14 & 29 & 7 & 50 \\
\hline & B & 37 & 13 & 0 & 50 \\
\hline & & 51 & 42 & 7 & 100 \\
\hline
\end{tabular}

ROM: Range of Motion, ER: External Rotation, IR Internal Rotation.

ROM-ER (P 0.00), ROM-IR (P 0.00)

In ROM total, some of the patients from group A were able to obtain score from 32-40 whereas group B patients failed to obtain these high scores (P 0.00). (Table 4)

Table 4. ROM Total

\begin{tabular}{|r|r|r|r|r|r|r|r|r|r|r|r|r|r|}
\hline & \multicolumn{10}{|c|}{ ROM-Total } & \multicolumn{1}{|c|}{ Total } \\
\cline { 2 - 12 } & \multicolumn{1}{|c|}{18} & 20 & 22 & 24 & 26 & 28 & 30 & 32 & 34 & 36 & 38 & 40 & \\
\hline \multirow{3}{*}{ Group A } & 0 & 1 & 1 & 9 & 8 & 3 & 7 & 5 & 4 & 8 & 3 & 1 & 50 \\
B & 3 & 3 & 8 & 15 & 16 & 4 & 1 & 0 & 0 & 0 & 0 & 0 & 50 \\
Total & 3 & 4 & 9 & 24 & 24 & 7 & 8 & 5 & 4 & 8 & 3 & 1 & 100 \\
\hline
\end{tabular}

ROM: Range of motion (P 0.00 )

Some patients from group A were seen lifting even 8-9 kg 
weight which was not seen in group B patients. (P 0.00). (Table 5)

Table 5. Power $(\mathrm{KG})$

\begin{tabular}{|c|c|c|c|c|c|c|c|}
\hline & \multicolumn{6}{|c|}{ Power $(K G)$} & \multirow[t]{2}{*}{ Total } \\
\hline & 4 & 5 & 6 & 7 & 8 & 9 & \\
\hline & 7 & 16 & 13 & 10 & 3 & 1 & 50 \\
\hline & 15 & 27 & 5 & 3 & 0 & 0 & 50 \\
\hline Total & 22 & 43 & 18 & 13 & 3 & 1 & 100 \\
\hline
\end{tabular}

(P 0.00)

In MCS 1 week total the mean score was 66.00 (SD $11.57 \pm 1.63)$ in group A and 53.54 (SD 7.51 \pm 1.06$)$ in group B (P 0.01). In MCS 6 week total the mean score was 78.68 (SD $10.34 \pm 1.46)$ in group A and $67.30(\mathrm{SD} 6.73 \pm 0.95)$ in group B (P 0.00$)$.

\section{DISCUSSION}

Mean age of patients was around 57 years similar to that reported in several other studies ${ }^{1,427}$. In our study, we noted male predominance ( 57 male and 43 female) where as some workers have found females to be more affected ${ }^{3,6-8}$. This difference could be due to difference in sample size. Most of our patients presented at around 10 weeks where as in a series reported by Michael et $\mathrm{al}^{27}$, average time for presentation was 26 weeks. This difference could be due to easily available consultation with orthopedic surgeon in our country where patients can directly seek specialized care. In both groups left side was more affected and non-dominant side was more often involved as compared to dominant side. These observations were similar to that noted by other workers ${ }^{6,7}$. In total 26 patients were diabetic, near similar in frequency as reported by Hannafin et $\mathrm{al}^{2}$.

Statistically significant differences were noted between two groups in terms of pain relief as reported earlier by Wei-Chun Hsu et $\mathrm{al}^{20}$. Similarly, the difference in ease of performing ADL between two groups was statistically significant, patients in Group A performing better. We could not find any report where performance of ADL has been compared. Six weeks after intervention, 24 patients in group A rated their results as excellent and 26 as good whereas 42 patients of group B could rate their outcomes as fair. This was highly significant statistical difference between two groups (P 0.00). We could not compare our observations with that of other workers since no such information was available.

Statistically significant differences were observed between two groups in range of different movements of shoulder. 15 patients in group A had range of shoulder flexion between 150-1800 whereas none had this range in group B. In a series reported by Michael et $\mathrm{al}^{27}$, forward flexion at 6 weeks was 1280 for intra-articular steroid group and 1020 for intraarticular lignocaine group. Thirty four patients in group A were able to abduct their arm between 120-1800. In contrast, only 7 patients in group B were able to abduct their arm to this extent where as Michael et al27 have reported 80.30 abduction in intra-articular steroid group and 730 in intra-articular lignocaine group. We could not find any studies where range of external rotation, internal rotation or total range of shoulder movement has been reported. Also there were no reports on outcomes in terms of ability to lift weight by affected upper limb and Constant-Murley Scores at 1 week.

In our series total mean score in Constant-Murley Score at 6 weeks was 78.68 in group A and 67.30 in group B and was significant statistically. Our results are superior to that reported by Michael et al27 where CMS at 6 weeks was 56.8 for intra-articular steroid group.

This suggests that intra-articular injection of lignocaine along with steroids does play a role in overall early recovery of patients. Intra-articular injection of corticosteroid with lignocaine immediately before physiotherapy session could provide immediate pain relief during the subsequent capsulestretching and joint-mobilization program which gives psychological boost to the patients to continue physiotherapy, thus achieving greater improvement in ROM and functional ability in comparison to intra-articular injection of corticosteroid and physiotherapy alone. Once the patients are able to move their shoulder, their fear and pain on movement also decreases. This improves compliance and results in better post-treatment outcomes. Since physiotherapy is prime modality of treatment, immediate pain relief is a major determinant for patients to carry out exercises ${ }^{20}$. Sooner physiotherapy is started better is the outcome. A practical approach of intra-articular injection of lignocaine and corticosteroid followed by stretching exercises and joint mobilization is a better method because it is quick and simple procedure.

\section{CONCLUSION}

Our observations suggest that intra-articular injection of lignocaine along with steroid plays an important role in early recovery of patients suffering from frozen shoulder. Immediate pain relief provided by lignocaine helps to boost up patient's confidence and convince them to start physiotherapy immediately. We have presented data about the events happening in six weeks time and found that lignocaine can play an important role in immediate recovery. The long term efficacy of lignocaine and its value cannot be proved at this stage. Further studies, done for longer period of time, are required to clear the issue. 


\section{REFERENCES}

1. Binder AI Bulgen DY, Hazleman BL, Roberts S. Frozen shoulder: a long-term prospective study Ann Rheum Dis. 1984;43:361-4.

2. Hannafin JA Chiaia TA Adhesive capsulitis: a treatment approach. Clinical Orthopaedics. 2000;372:95-109.

3. Lorbach O Anagnostakos K, Scherf C, Seil R, Kohn D, Pape D. Nonoperative management of adhesive capsulitis of the shoulder: oral cortisone application versus intra- articular cortisone injections J Shoulder Elbow Surg. 2010;19:172-9.

4. H Stam. Frozen Shoulder: A review of current concepts. Physiotherapy. 1994;80:588-99.

5. Binder AI Bulgen DY, Hazleman BL, Parr G, Roberts S. A controlled study of oral prednisolone in frozen shoulder. British Journal of Rheumatology. 1986;25:288-92.

6. Neviaser RJ Neviaser TJ The frozen shoulder: diagnosis and management. Clinical Orthopaedics 1987;223:59-64.

7. TD Bunker. Frozen shoulder. In: Bunker TD, Schranz PJClinical Challenges in Orthopaedic. the shoulder Oxford: Isis. 1998. 135-57.

8. Woodward TW Best TM. The painful shoulder: part II. Acute and chronic disorders. Am Fam Physician. 2000;61:3291-300.

9. D Thierry. Adhesive capsulitis. Emedicine. 2005;11:7.

10. TD Bunker. Time for a new name for frozen shoulder-contracture of the shoulder. Shoulder and Elbow 2009;1:4-9.

11. BJ Lundberg. The frozen shoulder. Acta Orthopaedica Scandinavica 1969;119:1-59.

12. Hand C Clipsham K, Rees JL, Carr AJ. Long-term outcome of frozen shoulder. JShoulder Elbow Surg. 2008;17:231-6.

13. RG Grey. The natural history of "idiopathic" frozen shoulder. J Bone Joint Surg Am 1978;60:564.

14. O'Kane JW Jackins S, Sidles JA, Smith KL, Matsen FA 3rd Simple home program for frozen shoulder to improve patients assessment of shoulder function and health status. J Am Board Fam Pract. 1999; 12:270-7.

15. Shaffer B Tibone JE, Kerlan RK. Frozen shoulder. A long-term follow-up. JBone Joint Surg Am. 1992;74:738-46.

16. Harryman DT II Lazarus MD. The stiff shoulder. In: Rockwood CA Jr, Matsen FA III, eds. The Shoulder Philadelphia: WB Saunders. 2004:1121-72.

17. Dundar U Toktas H, Cakir T, Evcik D, Kavuncu V Continuous passive motion provides good pain control in patients with adhesive capsulitis. International Journal of Rehabilitation Research. 2009;32(3):193-8.
18. Buchbinder R Green S, Youd JM. Corticosteroid injections for shoulder pain. Cochrane Database Syst Rev. 2003;1: CD 004016.

19. Carette S Moffet H, Tardif J. Intraarticular corticosteroids, supervised physiotherapy, or a combination of the two in the treatment of adhesive capsulitis of the shoulder: a place bocontrolled trial. Arthritis Rheum. 2003;48:829-38.

20. Hsu W-C Wang T-L, Lin Y-J, Hsieh L-F, Tsai C-M, Huang $K-H$ (2015) Addition of Lidocaine Injection Immediately before Physiotherapy for Frozen Shoulder: A Randomized Controlled Trial. PLoS ONE 10(2): e0118217. doi:10.1371/journal. pone. 0118217

21. Griggs SM Ahn A, Green A. Idiopathic adhesive capsulitis: a prospective functional outcome study of non-operative treatment. Journal of Bone and Joint Surgery (American). 2000;82:1398-407.

22. J Wies. Treatment of eight patients with frozen shoulder: a case study series. Journal of Bodywork and Movement Therapies. 2005;9:58-64.

23. Yang JI Chang CW, Chen SY, Wang SF, Lin JJ. Mobilisation techniques in subjects with frozen shoulder syndrome: Randomized multiple treatment trial. Physical Therapy. 2007:87:1307-15.

24. Maricar NK Chok BA Comparison of the effect of manual therapy with exercise therapy alone for stiff shoulder. Physiotherapy Singapore. 1999;2:99-104.

25. Miller MD Wirth MA, Rockwood CA. Thawing the frozen shoulder: the "patient". Clinical Orthopaedics. 1998;19:84953

26. Constant CR Murley AHG. A clinical method of functional assessment of the shoulder. Clin Orthop. 1987;214:160-4.

27. Michael J. Griesser MD, Joshua D. Harris, MD, Jonathan E. Campbell, MD, and Grant L. Jones, MD. Adhesive Capsulitis of the Shoulder: A Systematic Review of the Effectiveness of IntraArticular Corticosteroid Injections. J Bone Joint Surg Am. 2011;93:1727-33 